\title{
Sowing the future: A better understanding of Corporate-Indigenous Community Economic Partnerships in the Québec forestry sector
}

\author{
by Helin Dura ${ }^{1 *}$, Jean-Michel Beaudoin ${ }^{1}$ and Thierry Rodon²
}

\begin{abstract}
A major challenge for the forestry sector is providing Indigenous communities a fairer share of benefits resulting from forest-based development. This can be achieved by building Corporate-Indigenous Community Economic Partnerships (CICEPs). However, this avenue requires a better understanding of: 1) the structures that Corporate-Indigenous Community Economic Partnerships (CICEPs) can take and the impact of these structures on the relationship between both parties; and, 2) the necessary capitals for the creation of CICEPs so that they can meet the criteria of equitable sharing, while generating mutually profitable benefits. To address these knowledge gaps, we conducted a qualitative research involving 21 semi-structured interviews with Indigenous and industry representatives located in Québec, Canada. CICEPs can be divided into four structures: informal agreement, service contracting relationship, memorandum of understanding and joint venture. These partnerships can be translated into different forms of capital: human, social, political and financial. To promote and maximize CICEPs, it is necessary to link the structure-based approach with the capital-based approach. This research shows that more structured partnerships require larger investments in various forms of capital.
\end{abstract}

Keywords: Québec, Indigenous, First Nations, economic partnership, natural resources, forestry

\section{RESUMÉ}

Un défi important pour le secteur forestier est d'accorder aux communautés autochtones une part plus équitable des avantages résultant du développement économique qui en découle. Dans cette étude nous cherchons à savoir: 1- Quelles sont les structures que peuvent prendre les Partenariats Économiques entre les Communautés Autochtones et l'Industrie forestière (PECAI) et quelle est l'incidence de ses structures sur la relation entre les parties ? et 2- quels sont les capitaux nécessaires à la création de PECAI, afin qu'ils puissent répondre aux critères de partage équitable, en générant des retombées mutuellement profitables? Pour y arriver, des entrevues semi-dirigées ont été réalisées auprès de 21 représentants du milieu industriel et autochtone, localisés dans la province de Québec. Quatre structures sont observées et décrites : la relation informelle, l'entente contractuelle, l'entente de principe et la coentreprise. Les investissements nécessaires à la création des différentes structures de PECAI prennent la forme de capitaux : humain, social, politique et financier. Pour favoriser la réussite des PECAI, cette étude montre l'importance de considérer à la fois la structure que les investissements en capitaux. Les résultats suggèrent que les partenariats plus structurés nécessitent des investissements plus importants dans diverses formes de capital.

Mots clés : Québec, Autochtones, Première Nations, partenariat économique, ressources naturelles, foresterie

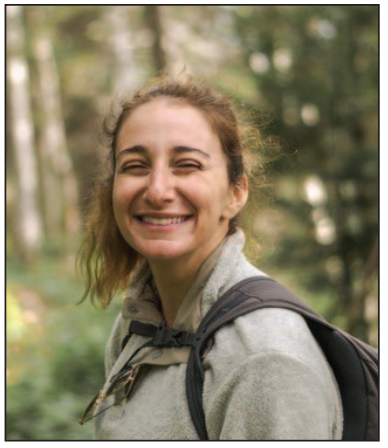

Helin Dura

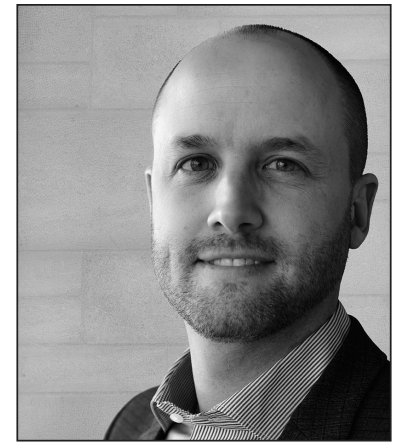

Jean-Michel Beaudoin

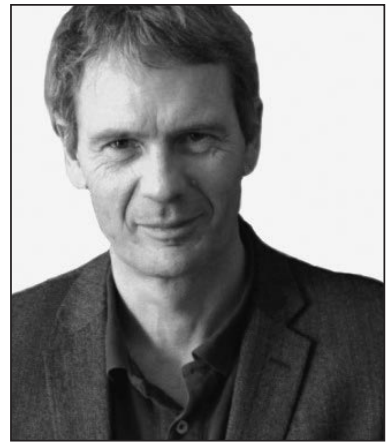

Thierry Rodon

1Department of Wood and Forest Sciences, Université Laval, Québec City, QC G1V 0A6, Canada; * Corresponding author: helinsubhi.dura.1@ulaval.ca

${ }^{2}$ Department of Political Sciences, Université Laval, Québec City, QC G1V 0A6, Canada 


\section{Introduction}

The Truth and Reconciliation Commission of Canada (2015) calls upon the corporate sector to adopt the United Nations Declaration on the Rights of Indigenous Peoples as a reconciliation framework, and in particular to:

Ensure that Indigenous peoples have equitable access to jobs, training, and education opportunities in the corporate sector, and that indigenous communities gain long-term sustainable benefits from economic development projects. (p. 9)

Governments are also pressured by the Commission, as well as by Indigenous organizations, to increase Indigenous participation in a varity of economic development projects (WGNRD 2015). In the same way, Indigenous peoples are engaging in a diverse range of economic models, arrangements and activities, particularly in the natural resource sectors (Coates and Crowley 2013; Belayneh et al. 2018). Because of its importance in the Canadian economy as well as its geographic proximity to many Indigenous communities, forestry is often considered as a strategic avenue to address poverty among these communities (Beaudoin $e t$ al. 2009, 2015a, 2015b; Bullock et al. 2020). Yet there still exists a number of barriers preventing Indigenous peoples in Canada to benefit from forestry and natural resource development (Lawler and Bullock 2017; Robitaille et al. 2017). Therefore, Indigenous communities are giving more consideration to the notion of "benefit sharing" (Wilson 2019). Within natural resource sectors, benefit sharing can include notably revenue distribution as well as job and business creation (Belayneh et al. 2018; Rodon et al. 2018). However, a lack of "capacity" among Indigenous peoples is most often cited as the key barrier. This paper focuses on the economic partnership as a collaborative process in which two or more parties share the risks, the resources, and the decision-making power in order to reach common and project-specific goals (McQuaid 2000).

In the field of forestry, the concept of Corporate-Indigenous Community Economic Partnerships (CICEPs) can help to answer the calls for the inclusion of local communities' interests, concerns and needs relating to the economic development of forest resources (Kant 2003). To do this, many studies suggest going beyond the classical theory of economic development and to document contextualized knowledge of CICEPs (Hindle 2010; Kayseas et al. 2015). Some studies are pushing for a definition of "Indigenous economic development" that encompasses Indigenous community involvement, knowledge, values education and culture (Boyd and Trosper 2010; Beaudoin et al. 2016;). Indeed, there are several reasons to be involved in a CICEP (Hickey and Nelson 2005; WGNRD 2015), both from the community and the industry perspectives. For the community, it provides a plethora of economic and social benefits. Economically, it increases employment rates and revenues which can improve the community's socioeconomic conditions (Wilson and Graham 2005; O'Faircheallaigh 2010; Mills and Sweeney 2013; Proulx et al. 2020). It also creates a favorable environment for building capacity in terms of operation and/or management skills (Boyd and Trosper 2010; Blackman 2017). More specifically, collaboration can help both the industry and the community attract qualified Indigenous workers (Théberge et al. 2019), notably by implementing better human resources practices. Research sheds light on initiatives that allow Indigenous people to have better access to culturally safe services and spaces in a work environment (e.g., free from racism and discrimination). Socially, building CICEPs can lead to better compatibility between financial goals and cultural preservation (Fortier et al. 2013; Beaudoin et al. 2015a). The long-term benefits of CICEPs include improvements in social, health, as well as educational and cultural services (O'Faircheallaigh 2010).

For the industry, CICEPs can ensure sustainable growth in the field of natural resources development (Hickey and Nelson 2005; Robitaille et al. 2017) . In the short and medium terms, CICEPs help the industry to meet workforce needs from demographically growing communities (Anderson 1997; Missens et al. 2007; Blackman 2017; Proulx et al. 2020) and help address the legal compliance around Indigenous rights and traditional territories (O'Faircheallaigh 2010; Gibson and O'Faircheallaigh 2015). In the long-term, CICEPs allow the industry to enhance its reputation and improve its relationships with communities, two major factors that facilitate access to natural resources (Mayers and Vermeulen 2002; Boyd and Trosper 2010; Beaudoin et al. 2015a; Blackman 2017).

Despite their considerable benefits, CICEPs are far from a perfect solution. Considering that economic development exists within a stochastic environment and is exposed to failures and resistance, there is a need to consider economic, environmental and social risks (Wilson 2019). CICEPs can be greatly affected by various factors such as cultural gaps, economic context, geographic location and politics. Moreover, differences in worldviews between Indigenous communities and the industry is another important factor to consider (Booth and Skelton 2011). While communities see themselves as part of the land and their culture is intertwined with the land (Adam et al. 2012), corporations, as well as mainstream society, often see themselves as external to forest ecosystems from which they mainly extract resources and acquire economic benefits. Generally, the industry is focused on the forest economic dimension while Indigenous economic development must support community economic, social, environmental and cultural values (Maclean et al. 2015). Many studies show that mining and forestry activities can affect relationships and ties between the territory, the environment and Indigenous communities (Adam et al. 2012; Belayneh et al. 2018). This divergent view of economic development can create conflicts between and among communities, especially for the ones with weakened social cohesion and lacking common ground with the concerns of their members.

CICEPs can also be affected by the country's economic context and have to contend with unpredictable market risks, trends and forces (Wilson and Graham 2005; Parkins et al. 2006; Booth and Skelton 2011). On the one hand, a healthy market and more resources to invest might encourage positive interactions, resulting in potentially successful CICEPs (Proulx et al. 2020). Industrial partners may also be more inclined to listen to what communities have to say and invest in new initiatives if they are not financially stressed. On the other hand, difficult economic and political conditions, such 
as economic crises, could generate negative reactions and reduce the room for maneuver of potential partnerships.

Geographic barriers may also become very important, especially in the building of human capital (Booth and Skelton 2011; Blackman 2017). Thus, a community located far from industrial operations may lose opportunities or have more difficulties accessing real benefits related to the forest industry (Begay Jr et al. 2007). A community's remoteness also has an impact on the access to education services and therefore, on the availability of skilled and qualified labor. As a result, the most educated communities tend to be located close to major urban centers (Proulx and Diallo 2016).

Lastly, it is important to address the question of politics (Robitaille et al. 2017), for example, the level of involvement and control of Indigenous communities in CICEPs. The last few decades have witnessed important improvements in the recognition of Indigenous rights, notably the United Nations (UN) Declaration on the Rights of Indigenous Peoples (UNDRIP 2007). As noted by Wilson (2019):

"a growing awareness of the lack of fairness or equity in the standard resource development model is now compelling Indigenous communities to urge governments and companies to: (a) ascertain how communities envision their future in relation to extractive industries, and whether or not they want resource development to take place on their lands; and, (b) to ensure appropriate decision-making powers and adequate benefit sharing, if developments are to take place."

Treaties between Indigenous communities and governments serve to frame the definition of rights for each stakeholder. In the province of Québec, the only official treaty to date is the James Bay and Northern Québec Agreement of 1975 (Rynard 2000). In the absence of this type of agreement, other nations are in a position where they must constantly reaffirm their rights. This can complicate the settlement of economic partnerships, as it can leave communities reluctant to engage in formal CICEPs because of political concerns. "All forms of rights are contestable and must be continually exercised" (Kayseas et al. 2015). It is possible to assume that being officially involved with a forestry company may compromise the way communities want to exercise their rights, and can also affect the rights for which they are seeking recognition. Some communities may be reluctant to make official commitment with the industry, especially when negotiations on the recognition of Indigenous rights are under way between various communities and the government. Yet, the current legal circumstances could foster opportunities for Indigenous employment. For example, Impact and Benefit Agreements (IBAs), now a standard feature in resource development projects in Canada, have created incentives for employers to give better opportunities for Indigenous workers (O’Faircheallaigh 2010; Caron et al. 2019).

Despite the above-mentioned limitations, CICEPs have the potential to create a common language between the industry and the communities, especially in the context of emerging markets such as the sector of bio-products (Bullock et al. 2020). There is a bewildering number of collaborations between Indigenous communities and the Canadian forest sector (Wyatt et al. 2010). Yet, available information on this topic is limited, outdated, widely dispersed and very little of it focuses on the forest industry specifically (Hickey and Nelson 2005). Thus, "[...] comprehensive, consistent and reliable information is difficult to find" (Fortier et al. 2013).

\section{Conceptual framework}

Research suggests two main analytical approaches for examining CICEPs: The structure-based approach and the capitalbased approach. The first focuses on the main structural arrangements of CICEPs and has been mainly viewed as a strategy to capture the existing forms of economic partnerships between communities and the forest industry (Fortier et al. 2013). Many studies indicate the need to further consider the procedural and contextual underpinnings of CICEPs in order to better understand the evolution of partnership relationships over time. Therefore, the second approach explores the extent to which Indigenous communities and forest companies engaging in CICEPs use diverse forms of capital into their relationship building. Although each approach can bring a different eye to the subject of this research, it is important to highlight the fact that they are not in opposition and our study aims to combine both approaches in order to better understand how to create fair and mutually beneficial CICEPs.

\section{The structure-based approach}

This first approach suggests four common types of formal agreements, i.e., 1) service contracting relationships, 2) cooperative business arrangements, 3) memoranda of understanding, and 4) joint ventures. Table 1 summarizes the characteristics and limits of these structures (Mayers and Vermeulen 2002; Hickey and Nelson 2005; Boyd and Trosper 2010; Mills and Sweeney 2013; McCreary et al. 2016; Craik et al. 2017).

The structure-based approach has been extensively analyzed and summarized in the literature. Therefore, we will not be pursuing our explanation further. If this approach is to succeed, we suspect it will be due to different forms and levels of investments in the relationship. Thus, we will focus on the link with a second approach, namely the capital-based approach.

\section{The capital-based approach}

The capital-based approach is inspired by other approaches such as the community capital (Flora and Flora 2013), and sustainable rural livelihoods (Scoones 1998). In this vein, it can be described as a "bottom-up approach" as it relates to the concept of empowerment (Perrault and Stevenson 2008). More importantly, it is building on several studies that used similar theoretical choices in the context of natural resource management (Beckley et al. 2008; Perrault and Stevenson 2008; Bombay 2010). The capital-based approach provides a comprehensive framework to explore a topic with little coverage in forest sciences, but predominant in practice (Wyatt et al. 2010) .

The capital-based approach implies that CICEP stakeholders have access to certain resources, which become capital when invested toward particular goals related to CICEPs. For the purpose of this paper, CICEPs can rely on four different forms of capital to initiate actions: human, social, politi- 
Table 1. Main structures of CICEP

\begin{tabular}{|c|c|c|}
\hline Structure & Key characteristics & Limitations \\
\hline Service contracting relationships & $\begin{array}{l}\text { - } \uparrow \text { Employment } \\
\text { - } \uparrow \text { Access to the workforce } \\
\text { - } \downarrow \text { Conflicts } \\
\text { - } \uparrow \text { Profits and resource access oriented } \\
\text { - } \uparrow \text { Short-term }\end{array}$ & $\begin{array}{l}\text { - Not efficient in creating deep and fair } \\
\text { corporate-community relationships } \\
\text { - Insufficient degree of attention to the various } \\
\text { needs of the communities, such as cultural } \\
\text { concerns }\end{array}$ \\
\hline Cooperative business arrangement & $\begin{array}{l}\text { - } \uparrow \text { Separate ownership } \\
\text { - } \uparrow \text { Capacity building } \\
\text { - } \uparrow \text { Commitment }\end{array}$ & $\begin{array}{l}\text { - Not efficient in creating fair CICEPs } \\
\text { - Insufficient degree of attention to the various } \\
\text { needs of the communities, such as cultural } \\
\text { concerns }\end{array}$ \\
\hline Memorandum of understanding & $\begin{array}{l}\text { - } \uparrow \text { Defines a set of rights and obligations } \\
\text { - } \uparrow \text { Principles and terms } \\
\text { - } \uparrow \text { Usually includes other forms } \\
\text { of arrangements }\end{array}$ & $\begin{array}{l}\text { - Can be used as false promises-It does not have } \\
\text { legal regulatory obligations }\end{array}$ \\
\hline Joint venture & $\begin{array}{l}\text { - } \uparrow \text { Financial benefits } \\
\text { - } \uparrow \text { Employment } \\
\text { - } \uparrow \text { Capacity }\end{array}$ & $\begin{array}{l}\text { - Usually implies an important financial } \\
\text { commitment } \\
\text { Does not fully meet the development needs of } \\
\text { Indigenous peoples - i.e. traditional values and } \\
\text { involvement of community members }\end{array}$ \\
\hline
\end{tabular}

cal and financial. Other forms of capital are mentioned in the literature, notably natural capital that is crucial to shaping the future of Indigenous forestry, but less important in the context of this particular research.

Human capital is the knowledge, education, training, personal skills and professional expertise of people (Flora and Flora 2013). Human capital puts emphases on the leadership qualification of shaping inclusivity and participation within the community which can be attributed to two crucial factors: workforce and key people. Indigenous communities present an age demographic that is favourable to CICEPs (Anderson 1997; Missens et al. 2007; Blackman 2017). Still, these communities also encompass individuals that have their own cultural needs regarding work environment, schedules, and training programs (Anderson 1997; Sosa and Keenan 2001; Hickey and Nelson 2005; Robitaille et al. 2017). Therefore, some strategies are necessary to create a secure work environment such as alternative training and skill development methods, liaison, and valuing Indigenous culture in the workplace (Caron et al. 2019; Proulx et al. 2020).

Social capital can be described as the features of organization such as work ethics, norms, values and trust, and are the result of collectively and socially negotiated ties and relationships (Perrault and Stevenson 2008). It is the "glue" bringing together people and developing a social network between organizations whose cultural, social, and economic interests are sometimes different (Putnam 2004; Emery and Flora 2006). The parallels between social capital and successful Indigenous economic development have been noted in the literature (Begay Jr et al. 2007; Trosper et al. 2008; Beaudoin et al. 2015a; 2015b). Some investments in social capital include: establishing communication and consultation mechanisms (Missens et al. 2007; Blackman 2017); developing a clear strategy (Petrucci and Tallman 2011; Blackman 2017); periodical assessment and monitoring of expected results (Sosa and Keenan 2001; Cornell and Kalt 2007; Craik et al. 2017). They are also fundamental components for the long-term success of the CICEP, and furthermore, have been found effective in avoiding potential conflicts.

For the purpose of this paper, we define political capital as the translation of values and requirements into standards and official rules (Flora and Flora 2013). The literature suggests that, in their initial stages, CICEPs can be short-term and objective-specific, but they can also be long-term and relationship-specific by having decisions made through consensus and negotiation (Begay Jr et al. 2007; Perrault and Stevenson 2008; Beaudoin et al. 2015a). It is also the capacity and the capability of the people to make their voice heard and to create opportunities that can benefit their community (Aigner et al. 2001). In the context of resource management, research shows that one's capacity to improve social equity depends on who participates and how, as well as who holds tenure and legal rights (Mahanty and McDermott 2013). Trosper et al. (2008) also found that a strong separation of business management from band governance and participation in business management planning can affect positively the profit of enterprises involving both Indigenous and industry partners. In sum, political capital refers to inclusion and power and, for this research, to how partners hold themselves accountable.

Financial capital is the measure of income generation and expenses and can be translated into capital goods, physical objects and financial instruments (Flora and Flora 2013). Financial capital is used to create capacity-building, business development, entrepreneurship and wealth generation (Emery and Flora 2006). In addition to the barriers created by the Indian Act, the Canadian banking system is also highlighted as a major barrier to Indigenous economic development (Bullock et al. 2020). Hence, the lack of financial capacity can be an important barrier when it comes to their 
participation in capital-intensive industries. Therefore, being involved in an economic partnership gives the community better access to financial tools and greater autonomy (Beaudoin et al. 2009, 2015a, 2015b; Boyd and Trosper 2010). In this vein, joint ventures are a form of partnership that requires a great level of community involvement and significant financial investments.

The capital-based approach is far from perfect; we acknowledge certain limitations as they are reflected by the literature. One limitation is the deterministic and simplistic aspects of the Bourdeusian theory (Jourdain and Naulin 2019). For example, the fact that social actors are constrained by the capital at their disposal. Other authors also highlighted that the concept of capital reflects a neo-classical paradigm (Caillé 1981), a long-time dominant thought in forest economics with a maximizing rational where "society is a mathematical aggregation of homogeneous rational agents" (Kant 2003 , p. 40). Indeed, Bourdieu's theory stipulates that individuals are not rational beings and that they are guided by habit. According to Caillé (1981), the use of the concept of capital can lead to a reduction in the diversity of human behavior and therefore simplifies individual actions and culture into limited socio-economic infrastructure (Lebaron 2003). In that same vein, Gudeman (2008) emphasizes that all values are not commensurable, that is to say, not all values can be compared using the same unit of value and values are not always interchangeable. Nevertheless, we believe that the capital-based approach is well-suited for knowledge users in the field of forestry. As mentioned previously, it has been tested and repeatedly used by an increasing amount of research related to community development, Indigenous forestry and forest management.

This paper explores the link between the structure-based approach and the capital-based approach. Hence, this study states that the more complex the structure in terms of profit, financial benefits, resource access and power-sharing, the stronger the need for investment in a broader variety of capital. Existing capital would be closely tied to the existing structure of partnerships and vice versa. For example, service contracting relationships can give access to less capital than joint ventures (Hickey and Nelson 2005). Yet it may be interesting to link how a CICEP's structural complexity can affect the capital needed to build those partnerships. To better understand the interaction between the capital-based approach and the structure-based approach and how it affects CICEPs, we deemed it necessary to explore the experiences resulting from actual partnerships. This paper analyses empirical data from CICEPs located in the province of Québec in order to answer the following questions: 1) What are the structures that Corporate-Indigenous Community Economic Partnerships (CICEPs) can take and what is the impact of these structures on the relationship between both parties? 2) What is the necessary capital for the creation of CICEPs so that they can meet the criteria of equitable sharing, while generating mutually profitable benefits? And, how do we create economic partnerships between Indigenous communities and the forest industry that are fair and mutually beneficial? We conducted semi-structured interviews with 21 Indigenous and industry experts who have all experienced different structures of CICEPs and the impact of these structures on their relationships with their partners. We also focused on how participants view the mobilization of capital (human, social, political and financial) in the CICEP they were involved in.

\section{Method}

Rather than studying specific cases, this study examines the perceptions and recommendations of key individuals who are involved in six different CICEPs and are well-known by their communities and organizations. In order proceed with our study, we had the method, the interview guide as well as the interview context approved by the Ethics Committee at Université Laval.

Between January 2019 and May 2019, we interviewed 21 forest industry and First Nations representatives. The study was conducted using semi-structured interviews. We used a non-probability purposive sampling, whereby participants were selected based on a prior set of criteria (experiences, location, and peer recognition) (Coyne 1997; Teddlie and Yu 2007). Sample size was determined according to the concept of saturation - when additional data isn't conducive to identifying new answers to our investigations (Creswell and Poth 2007). Participants were located in four of Québec's most important forestry regions: Mauricie, Côte-Nord, SaguenayLac-Saint-Jean and Northern Québec. We created an interview guide that targeted information about economic partnership structures and practices, the allocation of resources and development, as well as external factors affecting the partnership such as economic markets, communities and operation remoteness and education programs.

We used N'Vivo 12 software for the transcript analysis of interviews which were encoded as shown in Table 2. Moreover, to preserve the interviewees' confidentiality, we are not providing the type, nor the structure of CICEP they are involved in.

First, we applied a thematic analysis to identify relevant patterns that we categorized into main themes (i.e., capital) accordingly to our conceptual framework (Braun and Clarke 2006; Paillé and Mucchielli 2012). Second, we analyzed these main themes into sub-themes using data from the interviews in a way that provided answers to our research objectives while also staying close to the participants discourse. Finally, a conference was organized in November 2019 inviting all the

\section{Table 2. Description of the interviewees}

\begin{tabular}{llc}
\hline Characteristics & N & $\%$ \\
\hline Actors & & \\
$\quad$ Industry (FI) & 10 & 47.6 \\
$\quad$ First Nation (FN) & 11 & 52.4 \\
$\quad$ & \\
Region & & \\
$\quad$ Saguenay-Lac-Saint-Jean & 6 & 28.6 \\
$\quad$ Côte Nord & 8 & 38.1 \\
$\quad$ Nord du Québec & 4 & 19.0 \\
$\quad$ Mauricie & 3 & 14.3 \\
$\quad$ & & \\
Language & 19 & 90.5 \\
$\quad$ French & 2 & 9.5 \\
$\quad$ English &
\end{tabular}


participants to validate the findings of this study. They were presented with the interpretations of all the verbatims selected for this paper and provided evaluations and recommendations pertaining to our interpretation of the interviews contents. The participants approved their verbatims and were able to provide extra information, allowing for a better mutual understanding. We have ensured that all the further interview comments were added to the results section.

\section{Results \\ Structure of CICEPs}

Data analysis from CICEPs in Québec revealed four main structures: informal agreements, service contracting relationships, memoranda of understanding, and joint ventures. Compared to informal agreements, the other three structures are all formal and involve the recognition of CICEPs through official documents. However, our results show a clear distinction between joint ventures and the other structures of CICEPs as they often imply a greater level of human, social, political and financial involvement. Moreover, we observed that informal agreements are very important in laying the foundations for a solid long-term CICEP.

\section{Informal agreements}

Informal agreements indicate that a relationship has been established without the existence of a signed agreement or any official tool to track investments. According to five interviewees from the same informal agreement, it arose from the needs of both the industrial and the community partners and addressed a pressing situation related to the workforce and employment. Due to its informal nature, there was no official tool to monitor and evaluate the objectives and investments made by the partners. However, meaningful discussions and actions still took place showing that they were willing to work together, which allowed them to build a strong relationship over time.

Two industry interviewees told us that they have suggested an agreement and have been waiting to formalize it. They also said that, although they have been waiting a long time for the agreement to be signed, it does not stop them from working with the community.

"It has been at least four years since we first called to sign an agreement and it hasn't happened yet. I told them that I wouldn't wait for the agreement to be signed before getting things done." (5-FI) translated by the authors

All the community interviewees were satisfied with the informal CICEP and said that a signed agreement would not have an important impact:

"I don't think things will be different from the present once we sign the agreement. We already have a good relationship, and we understand each other." (12FN) translated by the authors

However, the industry interviewees believed that a signed agreement could motivate their organizations to do more. They emphasized the fact that a formal agreement makes it easier to justify the financial investment to their company executives, as well as to clarify the intentions of both sides:
"When you formalize it [the agreement], it provides an explanation to the company leaders. The agreement also makes it possible to clarify the intentions of both parties. Even if we have a draft agreement that seems to work, as long as it is not signed, we do not have the assurance that it is the case." (5-FI) translated by the authors

Community interviewees also highlighted the fact that it is sometimes easier to communicate with their informal agreement partners than it is with some companies with whom they have signed formal agreements. For these community interviewees, in other words, a formalized agreement is not a guarantee to ensure their interests are not prejudiced. The added value of having a signed agreement is not always clear. For the industry, a formalized agreement means much more, as it helps in having access to resources, getting forest certification and avoiding conflicts.

\section{Formal agreements}

Formal agreements are officialized with two types of documents. Sixteen interviewees were involved in such agreements. These were in the form of a memorandum of understanding (MOU) - an official document stating the interest of a company and a community to work together, or a service contracting relationship-explaining how to operate the CICEP.

For four of the participants, a conflict over land use triggered the search for common grounds and their decision to develop a formal agreement in the form of a MOU. This allowed for the opening of a communications channel. One participant mentioned that their agreement is a two-level process. The first level is strategic and calls for a formal statement of political strategy - i.e., in the form of a MOU. The second level is operational and articulates how things are going to be done - i.e., implementation of a service contracting relationship. A small number of those interviewed were involved in a service contracting relationship, although they were not yet part of a MOU.

Interviewees representing both industry and communities highlighted that service contracting relationships address specific goals. For industrial interviewees, they give access to labour and wood supplies. For Indigenous interviewees, they can be a vehicle for employment and wealth creation. A few interviewees mentioned that ensuing economic gains for the community can go beyond a project's financial performance. It can also create better social cohesion and lower the demand on the community's social services:

"The benefits are social too. If I get someone from the community to work, it will not only change his own life, as he will have better self-esteem and will become a better citizen, but his wife, children and extended family will benefit from this too. Ultimately, this will reduce the pressure on society and police. Everyone can benefit from this initiative. Yes, there are some indirect economic benefits, but we are mostly interested in the positive social impacts." (19-FN) translated by the authors 
Many interviewees mentioned that, although economic agreements seem to lead to consensus, they might present a certain level of risk. For example, they can be used as false promises. Since most of the provisions are not legally binding, risk management is a matter of judgment and trust between the partners, because the community and the industry don't have legal means to hold their partner accountable.

Joint ventures were presented as requiring a higher level of investments in term of capital. For most interviewees, this structure of CICEP is a business owned and managed by both the community and the industrial partner. In these ventures, the community has ownership over the business and its representatives sit on the administrative board. The community interviewees told us that they don't necessarily own a majority of shares, as long as it doesn't reduce their involvement in the decision-making process.

Several interviewees highlighted the fact that a joint venture it is often established subsequently after a formal arrangement such as a MOU. Partners have already experienced working together and have a clear framework for their relationship.

"So, it started with a land-use conflict that worsened and got far enough to receive media coverage. It finally resulted in a Memorandum of Understanding. This allowed us to better understand each other and to learn to work together. This is how our partnership started. When you're looking for partners, why wouldn't you go with the ones you already know and trust?" (8-FN). translated by the authors

Partners are more inclined to participate in a joint venture if they already know each other from previous experiences. This relies on the establishment of a personal relationship based on trust and confidence between the two partners.

The four interviewees who were part of the same joint venture told us that CICEPs do not work the same way with every community. Therefore, the success of a joint venture is largely affected by the economic culture of the community, referring to how the community opts in to the market economy and their experience in carrying out economic projects. The only joint venture studied was managed by a board of directors consisting of members from a forestry company and a community band council. The interviewees noted many advantages for the company to get involved in a joint venture: easier access to forest certification, human resources and social acceptability, ultimately, building a higher level of political capital. Interviewees also highlighted the fact that it could provide the community with lasting incomes which would allow them to assert their independence from government programs. One interviewee said that the self-generation of revenue allowed the community to be economically independent from the federal government and provided the community with substantial additional power. This power is of even greater consequence when the joint venture was located on the reserve.

"The community has a lot more say and a lot more of the decision-making power in the partnership than you would think they do. I would say, and again, when it is on reserve land, it is pretty difficult for the First
Nation to not have that type of control and interest, but again, not all JVs are on reserves." (21-FN)

Yet, joint ventures have limitations. According to one community interviewee, they do not leave space for land-use conflicts or any other profound divergence:

"It is not through economic participation that the issue of relations between forest companies and First Nations is solved. It can help; it creates different communication channels, but it doesn't solve land-use conflicts." (8-FN) translated by the authors

Thus, discussion relating to joint venture called upon all type of capital: human, social, financial, and political.

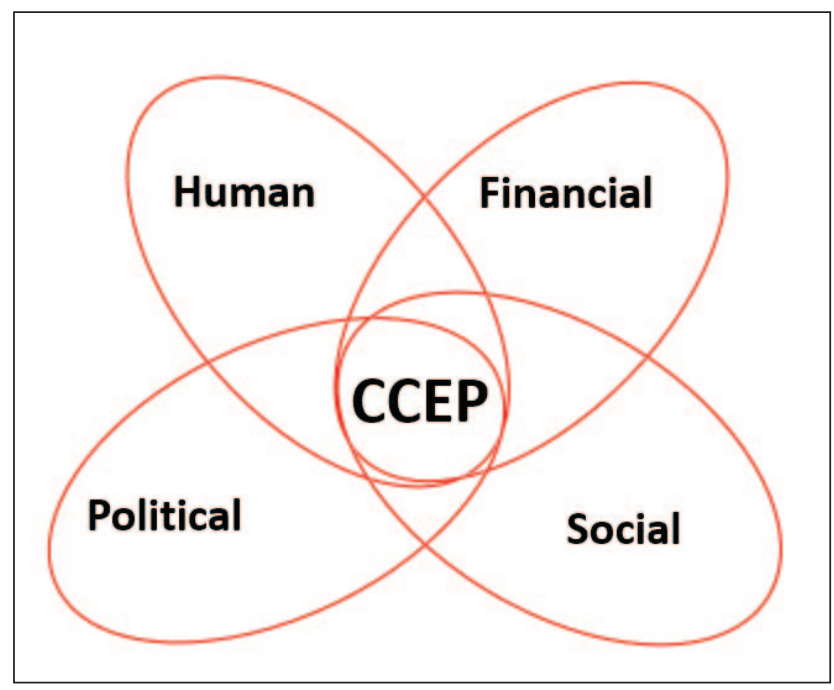

Fig. 1 The capital-based approach, adapted from Flora and Flora (2013).

\section{CICEP capital}

\section{Human capital}

Regarding human capital, three key elements emerged from the interviews: recruitment tools, the existence of key people, and training programs. Recruitment tools are a way to analyze and achieve the human capital objectives of a CICEP. Two community interviewees mentioned that recruitment is based on the industry needs.

"It is an agreement that focuses exclusively on industry needs in terms of human resources, workforce." (19-FN) translated by the authors

However, a few other community interviewees also noted that the decisions related to employment are taken jointly through an employment committee.

"There are some things that are done jointly and we also try, through our employment committee with the company, to boost the human resources. We're trying to link what we can offer with the company's needs." (3-FN) translated by the authors 
Industrial interviewees specified that their companies would organize employment events inside the communities for communication and recruitment purposes, notably by visiting secondary schools or by offering yearly school trips to the company's facilities. Industry interviewees described the distance between the community and company operations as a major obstacle to hiring Indigenous workers.

Most interviewees mentioned that creating positive economic relationships between the forest industry and Indigenous peoples requires key people. Having people with technical and professional capabilities is not enough. Key people with knowledge, know-how and life skills (e.g., individuals' attitude, relational competencies and communication capabilities) is crucial to moving the project forward. For example, such a person would have to be tactful, respectful and patient, notably when developing strategic plans that would include a greater degree of Indigenous participation. Community representatives particularly reported that their staff is quite busy and that they can only dedicate a limited fraction of their schedule to the development of these economic partnerships. They often have to wear different hats as they are solicited by several issues, projects and consultations at the same time.

The only joint venture studied was described, both by the community and the industrial interviewee, as a successful one due to key people involved in the CICEP. Those individuals shared the view that economic development can be a positive priority, while also being patient, dynamic and willing to share knowledge.

"They are patient shareholders who give a lot of their expertise and share their knowledge. It is shareholders that I find dynamic, but who do not have the sole objective of filling the pockets of their community." (6-FI) translated by the authors

Several participants mentioned that it is also important to have a number of contact persons rather than one main contact. Depending solely on one person can put the CICEP approach at risk in the case of the departure of this key person.

"What I often say to our people is that they shouldn't work with only one person who is the point of contact in a region because, if that person leaves or becomes sick, you don't have any contact inside the community anymore. The contact person, his role is to introduce other people, to introduce, to create other links between us and the community." (20-FI) translated by the authors

Some community interviewees have suggested hiring key Indigenous staff. These persons would play the role of expert coordinator and advisor in the CICEP process, as well as provide the advantage of knowing the community.

An important issue was raised among all the interviewees: the difficulty of working in a stressful environment with insufficient professional human resources. Community interviewees told us that they need more professional resources with higher capacities, while the industrial interviewees have reported sometimes being in a situation beyond their capabilities.
"My concern is that I lack staff. We have so much work. It takes a team, increase the team of professionals. I think there should be staff for the implementation of the partnership." (10-FN) translated by the authors

During the interviews, participants highlighted the importance of a positive training and working environment. Many noted the importance of awareness training sessions to provide information about Indigenous lifestyles and to introduce employees to each other. Some company participants have also created cultural awareness sessions for their senior staff, relying on external or local "experts".

\section{Social capital}

Results concerning social capital helped us identify three elements: strategy, communication and resource sharing. Many interviewees underlined the importance of a long-term strategy and comprehensive action plans to foster durable relationships between local Indigenous communities and the industrial forestry sector. If these elements need to include the interest of all parties, some Indigenous interviewees also mentioned that the strategy should find a balance between economic as well as land protection values.

Another important element was the timing of the benefits; short-term outcomes are a very important element of motivation for partners which bring encouraging results and keep partners motivated and committed to their agreement. However, long-term benefits have to be planned in order to give more sustainable results.

"I think it needs to be a long-term process. It's a lasting relationship. I think that we have to work on longer-term issues and aim for short-term results; I think that we have to be careful in the end, we should be looking for a long-term strategy." (18-FI) translated by the authors

"[The company] realizes that if they get along with the Indigenous [community], it will be easier in the future to get access to the resources, even if the wood volume is costlier now." (15-FN) translated by the authors

Several interviewees told us that the communication process is decided upfront, consistent, respectful and transparent. They suggested asking questions such as: How are we going to communicate? How often? Information about the project must be genuinely clear and easy to find.

Not all communities have equal access to financial, techni$\mathrm{cal}$ and professional expertise and participants explained that resource sharing refers to both expertise and material. Concerning economic development, some Indigenous interviewees seek expertise and experience from the industry. Industrial interviewees said that they can offer access to a reduced price on certain resources, free fieldwork information and qualified staff. Sharing competencies was a recurring element addressed by the interviewees. Interviewees said that offering these kinds of exchanges can build trust and satisfaction.

\section{Political capital}

We identified three elements based on the interviews: decision-making, conflict management and mitigation, and 
monitoring. First, interviewees said that decision-making must reflect the vision of both parties. The community should be able to participate in the process by including certain clauses in the CICEP (e.g., strategy and action plan). Several interviewees emphasized the importance of creating decision-making committees early in the CICEP process, notably for managing project finances, reporting project results or deciding on new investments. Indigenous interviewees mentioned that it is usually the industry that invests the financial capital in economic partnerships, and therefore such dynamics can lead to power-sharing issues:

"It still comes with certain limitations, because again, it is generally the company putting forward a lot of that capital in cash. Because the community doesn't have it at their fingertips. So there can be times where a community's representatives are sitting around the table but don't and aren't able to negotiate. Some companies will in fact, leverage that unfortunately". (21-FN)

To address this issue, interviewees suggested to jointly build a monitoring process to hold partners accountable for their (in)actions and to protect partners who put time and energy into a CICEP project.

"It protects everybody. This can stop people from doing as they please, regardless of the concerns of the other partners. It creates a kind of regulating phenomenon." (19-FN) translated by the authors

From the community perspective, interviewees said that the proportion of ownership in the company is not the only factor that affects their level of control and influence over the decision-making process. It is rather their level of expertise that is beneficial that matters. Community interviewees involved in the joint venture said that, while they only own $25 \%$ of the joint venture, their participation in decision-making is as strong as their industrial partner's because they are bringing an important amount of expertise. For some industrial participants, the biggest concern regarding economic partnerships remains the use of frontmen. It creates an unfair situation and causes a lot of frustration for those who are trying to follow the rules. Not only do people feel disadvantaged by this phenomenon, they do not feel recognized for their efforts and investments.

Interviewees noted that successful conflict management is also a way to avoid problems early on. For some, the best way to resolve conflict is to take the time to talk together. In general, the interviewees said that every community and company should have its own conflict resolution mechanism. However, the procedure should be decided at the beginning. Interviewees were aware that a conflict resolution protocol is required for the companies to obtain forest certification.

"This is something that stands out a lot when it comes to FSC certification and conflict resolution." (10-FN) translated by the authors

\section{Financial capital}

Results showed that financial capital is an important reason for communities to participate in CICEPs. We identified three elements: the creation of jobs, income and enterprises. A few community interviewees emphasized the importance of CICEP profitability and hence economic viability through job creation.

"The will of the community, when it comes to economic partnership, is simply to create jobs and wealth. It takes a viable and economically profitable project." (8-FN) translated by the authors

While a community interviewee mentioned that Indigenous communities could have more benefits by playing a bigger economic role in CICEP, several community interviewees mentioned that playing a smaller role (i.e., shareholding) can reduce their financial risk. They stressed that their main financial goal was to create revenue and jobs for their community, which is very important to attain selfdetermination.

On the industry side, some interviewees spoke about the importance of industrial participation to create opportunities for Indigenous entrepreneurship. They are aware of the difficulty Indigenous entrepreneurs face when it comes to having access to bank loans. For instance, they created joint ventures for equipment and machinery purchases at a 40-60 ratio, as described by the industry interviewees. This reduces financial risk and creates revenue.

"For Indigenous entrepreneurs, it is difficult to have access to financing in order to buy equipment. We have the money. We offer them the possibility of associating with us. For example, they own $40 \%$ and we have $60 \%$. They don't have to put themselves in a perilous financial situation, they have a weekly salary, they have advantages, if the company is doing well, they have $40 \%$ from the benefits and they can withdraw anytime. We now have thirty subsidiaries and it's fine." (17-FI) translated by the authors

\section{Discussion}

This study captured four types of partnership structures (i.e., informal agreements, service contracting relationships, MOUs, and joint ventures), and confirmed the relationship between them as mentioned in the literature (Fortier et al. 2013). For instance, an informal agreement can be the first step to a formal agreement (MOU/service contracting), which can evolve into an even more complex structure (joint venture). Sixteen of the Indigenous and industry interviewees were involved in MOUs from which service contracting relationships also emerged. If previous studies mentioned that conventional forestry may have little to offer in long-term economic development (Booth and Skelton 2011), this research endeavours to consider partnerships with multiple timelines. With this goal in mind, planning and monitoring become crucial for allowing a short-term oriented structure, such as service contracting, to evolve towards and into a more complex structured partnership and meet the longterm objectives and aspirations of Indigenous communities.

This paper also sheds light on the importance of informal agreements, which is under-explored in the literature. Informal agreements rely mainly on key individuals who can 
ensure that the values and priorities of both partners are taken into consideration (Schein 2010). Additionally, achieving benefits also depends on the quality of the relationships between the two partners. Thus social capital is also an important attribute in informal partnerships. It is the glue that brings partners together. Yet, in the informal agreement, the development of social networks is limited to individuals and their objectives. A greater formalization of the partnership, for example through a MOU, would perhaps make it possible to have resonance through the members of the organizations and over time, without however, being too coercive. Furthermore, we can argue that since an informal agreement (CICEP in its simplest form) calls for the mobilization of both human and social capital, they become the basis for formal structures of the CICEP, and it is important to make those investments before trying to formalize a CICEP through any type of formal agreement (service contracting, MOU or joint venture).

While our results concur with previous research that human capital is fundamental to CICEPs, (Anderson 1997; Sosa and Keenan 2001; Hickey and Nelson 2005; Missens et al. 2007; Blackman 2017), it is important not to depend solely on one key individual. This goes back to the importance of building an organizational culture made of values and priorities representing both partners. In a more structured CICEP, a contact person should be easy to replace, and more people might be expected to make the CICEP work. These findings are in line with the literature (Schein 2010; Beaudoin et al. 2015a, 2015b) and reveal many strategies to fill the gap.

To be effective, training strategies should be the result of a collaborative effort. As many researchers have suggested, teaming with governments to create suitable training programs and financial support ensures project continuity (Sosa and Keenan 2001; Missens et al. 2007; O'Faircheallaigh 2010; McCreary et al. 2016), and teaming with Indigenous communities is important for developing Indigenous employment (Théberge et al. 2019). The results also underline the importance of hiring Indigenous experts. This can help produce the right working environment with a flexible schedule and sensitivity to Indigenous culture (Sosa and Keenan 2001; Wilson and Graham 2005; Boyd and Trosper 2010).

This links with the importance of social capital, which is present in all CICEP structures. Communication and resource sharing must be sensitive to the community's needs, values and preferences, as widely acknowledged in the literature. Creating and maintaining dialogue is important, with annual meetings being conducted to plan future work, as well as to make the necessary adjustments regarding previous results. This is compatible with literature recommendations about having an efficient and periodic monitoring mechanism (Sosa and Keenan 2001; Cornell and Kalt 2007; Craik et al. 2017). And as trust is central to social capital, we show that CICEPs are also about enabling partners with tools, in particular for the industry as they must provide explanations when something fails or cannot be done and expectations are not met (Robitaille et al. 2017).

Moving to political capital, this study aligns with previous research that mentioned power distribution issues in collaboration between natural resource industries and Indigenous communities (Kernaghan 1993; Petrucci and Tallman 2011;
Hotte et al. 2019). We contribute by showing, in the context of CICEPs, the link between political and other forms of capital. While a community can assert control over a CICEP by the amount of ownership, the amount of expertise is also likely to influence decision-making processes. When a community invests in higher shareholding and has limited financial resources, it should pay attention to the trade-offs that could have more influence on decision-making processes by investing in their people (human capital) or their relationship with their partners (social capital).

As reported by Kayseas et al. (2015), the progress of Indigenous rights is creating more opportunities for Indigenous peoples to opt into economic development. Some communities can be reluctant to be formally involved in a CICEP because they do not want to compromise negotiations with governments regarding recognition of their rights. Thus, informal agreements can appear more attractive and safer for communities. Yet, it is the quality of the relationship (e.g., mutual trust) rather than the structure that will help to strike the right balance. The formalities introduced into cross-cultural relationships are an interesting topic, particularly regarding signed agreements. For industry representatives, this creates a more secure context that guarantees a follow-up on their financial and human investment. This perspective is often about securing assurances and reducing risk and uncertainties. Additionally, a formal agreement captures the commitment of senior management, which is essential for a diversity management policy to be effective (Proulx et al. 2020). For community representatives, it almost seems to be the opposite - almost dangerous and undesirable, given past agreements that were not honored. Community representatives cannot be clearer about their focus on relationships and actions, rather than officialized agreements. This finding could be interesting for future research, especially concerning the differences between the position of the community and the company regarding the risk incurred by an economic partnership according to the different partnership structures.

Accessing financial capital can be challenging for Indigenous communities (Beaudoin et al. 2009, 2015a, 2015b; Bullock et al. 2020). In such cases, maximizing profitability and minimizing financial risk was important for many Indigenous interviewees. As for the industrial interviewees, many were aware and sensitive to the financial situation of the communities and have suggested a higher financial involvement from the industry to ease the burden on Indigenous entrepreneurship. The same major barriers relating to the Canadian banking system as an important disadvantage to on-reserve Indigenous entrepreneurs and business development have been identified in recent literature (Bullock et al. 2020). Joint venture is the CICEP structure that requires a higher mobilization of financial capital. Both partners are involved in a commercial relationship and their investments should provide for long-term efficiency. Yet joint ventures are not a political tool, and other communication channels must be used in order to address conflicts over territory, land use and Indigenous rights. Economic involvement of Indigenous communities might help to create a better way to communicate but will not solve land-use conflicts.

Our results show that capital is not equally mobilized when establishing a CICEP. Partners appear to mobilize cap- 


\begin{tabular}{|c|l|l|l|l|}
\hline & \multicolumn{4}{|c|}{ Capitals } \\
\multirow{2}{*}{$\begin{array}{c}\text { Type of } \\
\text { CICEP }\end{array}$} & Human & Social & Political & Financial \\
\cline { 2 - 5 } $\begin{array}{c}\text { Informal } \\
\text { agreement }\end{array}$ & +++ & ++ & + & \\
\hline $\begin{array}{c}\text { Service } \\
\text { contracting }\end{array}$ & ++ & +++ & + & \\
\hline $\begin{array}{c}\text { Joint } \\
\text { venture }\end{array}$ & ++ & ++++ & ++ & +++ \\
\hline
\end{tabular}

Fig. 2 Relationship between the structure-based approach and the capital-based approach.

ital in the following order: human, social, political and financial. In addition, some forms of capital commonly addressed by the literature, (e.g., natural capital), were not mentioned by the interviewees regarding the implementation of economic partnership best practices. As stated at the beginning of this paper, the two approaches interact with one another. Informal agreements reflect the trust between partners and provide information about the quality of the relationship. Therefore, they could hardly exist without solid human capital. As we suspected, some structures require a broader range of capital. Thus, joint ventures seem to cover all capital while service contracting does not give access to political and financial capital. Yet structures and capital should not be seen as mutually exclusive. They can be interlinked and can create a starting point for one another. Fig. 2 is helpful in understanding the link between the CICEP structures and the existence of diverse forms of capital.

Finally, our results reveal a greater perception of risk on the part of forest companies. It concerns financial risk mainly; one explanation is that forest companies seem to play an active role to facilitate loans related to the purchases of operational equipment by Indigenous entrepreneurs. Industrial interviewees have often pointed out the financial risk that it represents for them. From the perspectives of Indigenous interviewees, CICEP represents a risk in the sense that a lot of their efforts are focused on channeling human capital to respond to the needs of the industry, while not feeling they have full control of the goals and means to get there. That being said, our results identify several elements to engage in a CICEP that contribute short- and long-term objectives of both partners.

\section{Conclusion}

In this paper, we sought to better understand how to create lasting, fair and mutually beneficial CICEPs through the viewpoints of 21 key participants as well as from the literature. However, there are some limitations to this study. It is important to highlight that the results do not take into consideration the full complexity and diversity of the Indigenous context nor of the forest industry, but rather help to understand the circumstances of successful CICEPs. Additionally, we interviewed participants that were engaged in building CICEPs. We did not, however, interview participants who experienced conflicts or failures in CICEPs, thus some information could have been missed.

The participation of Indigenous communities in the Canadian forest industry allows more equity and a better share of benefits between the two parties. Yet very little academic information exists on the topic. Moreover, the existing information is outdated. Social, economic and political reconciliation between Indigenous nations and the rest of Canadian society deals with far more than what was addressed in this paper. By looking at the involvement of Indigenous peoples in forestry development, this paper fosters better territorial management and provides more space for Indigenous discourse within the forest industry.

\section{Acknowledgements}

We would like to thank all the participants that took part of this research. Our work would not have been possible without the collaboration and the tremendous help from the indigenous representatives and representatives of the forest industry. For the sake of confidentiality, we cannot disclose their names. If this paper ever falls into their hands, may it remind them of the importance of our precious conversations. We hope that this paper will do justice to their speech and will highlight their effort in creating mutually profitable CICEPs. Finally, we also thank the Fonds de recherche du Québec for all the funding support.

\section{References}

Adam, M.-C., D. Kneeshaw and T.M. Beckley. (2012). Forestry and road development: Direct and indirect impacts from an aboriginal perspective. Ecol. Soc. 17(4): 1-13.

Aigner, S. M., C.B. Flora and J.M. Hernandez. (2001). The premise and promise of citizenship and civil society for renewing democracies and empowering sustainable communities. Sociol. Inq. 71(4): 493-507.

Anderson, R. B. (1997). Corporate/indigenous partnerships in economic development: The first nations in Canada. World Dev. 25(9): 1483-1503.

Beaudoin, J.-M., L. LeBel and L. Bouthillier. (2009). Aboriginal forestry entrepreneurship: A case study in Mashteuiatsh Ilnu Nation. For. Chron. 85(5): 783-788. https://doi.org/10.5558/ tfc85783-5

Beaudoin, J.-M., L. Bouthillier, J. Bulkan, H. Nelson and S. Wyatt. (2015a). Community-based enterprise as a strategy for development in Aboriginal communities: Learning from Essipit's Forest Enterprises. J. Aborig. Econ. Dev. 9: 24-40.

Beaudoin, J.-M., L. Bouthillier and G. Chiasson. (2015b). Growing deep roots: Increasing Aboriginal authority in contemporary forest governance arrangements. Land Use Policy 49: 287-295.

Beaudoin, J.-M., L. Bouthillier, J. Bulkan, H. Nelson, R. Trosper and S. Wyatt. (2016). What does "First Nation deep roots in the 
forests" mean? Identification of principles and objectives for promoting forest-based development. Can. J. Forest Res. 46(4): 508519. https://doi.org/10.1139/cjfr-2015-0170

Beckley, T. M., D. Martz, S. Nadeau, E. Wall and B. Reimer. (2008). Multiple capacities, multiple outcomes: Delving deeper into the meaning of community capacity. J. Rural Commun. Dev. 3(3): $56-75$.

Begay Jr, M. A., S. Cornell, M. Jorgensen and J.P. Kalt. (2007). Development, governance, culture: What are they and what do they have to do with rebuilding Native nations. In: Rebuilding Native nations: Strategies for Governance and Development, Tucson, The Arizona University Press. pp. 34-54.

Belayneh, A., T. Rodon and S. Schott. (2018). Mining economies: Inuit business development and employment in the Eastern Subarctic. North. Rev. (47): 59-78.

Blackman, J. (2017). Researching Indigenous partnerships: An assessment of corporate-Indigenous relations, R.A. Malatest \& Associates, Ltd., Ottawa. https://indigenousworks.ca/sites/ahrc/ files/attachments/Researching\%20Indigenous\%20PartnershipsMalatest\%20Final\%20Report-English-Oct\%202017.pdf

Bombay, H. (2010). Aboriginal human resource professional and skill development needs in the bioeconomy and environmental servicing. Nat. Ab. For. Assoc., Ottawa.

Booth, A. L. and N.W. Skelton. (2011). "There's a conflict right there": Integrating indigenous community values into commercial forestry in the Tl'azt'en First Nation. Soc. Natur. Resour. 24(4): 368 383.

Boyd, J. and R. Trosper. (2010). The use of joint ventures to accomplish aboriginal economic development: Two examples from British Columbia. Int. J. Commons 4(1): 36. https://doi.org/10.18352/ bmgn-lchr.132

Braun, V. and V. Clarke. (2006). Using thematic analysis in psychology. Qual. Res. Psychol. 3(2): 77-101.

Bullock, R., M. Zurba, J.R. Parkins and M. Skudra. (2020). Open for bioenergy business? Perspectives from Indigenous business leaders on biomass development potential in Canada. Energy Research \& Social Science 64: 1-10.

Caillé, A. (1981). La sociologie de l'intérêt est-elle intéressante? (à propos de l'utilisation du paradigme économique en sociologie). Sociologie du travail 23: 257-274.

Caron, J., H. Asselin and J.-M. Beaudoin (2019). Attitudes and behaviors of mining sector employers towards the Indigenous workforce. Resour. Pol. 61: 108-117.

Coates, K. and B.L. Crowley. (2013). New beginnings: How Canada's natural resource wealth could re-shape relations with Aboriginal people. MacDonald-Laurier Institute for Public Policy, Ottawa, Canada. https://www.macdonaldlaurier.ca/files/pdf/ 2013.01.05-MLI-New_Beginnings_Coates_vWEB.pdf

Cornell, S. and J.P. Kalt. (2007). Two approaches to the development of Native nations: One works, the other doesn't. In: Rebuilding Native nations: Strat. Govern. Dev. pp. 1-34.

Coyne, I. T. (1997). Sampling in qualitative research: Purposeful and theoretical sampling; merging or clear boundaries? J. Adv. Nurs. 26(3): 623-630.

Craik, N., H. Gardner and D. McCarthy. (2017). Indigenous-corporate private governance and legitimacy: Lessons learned from impact and benefit agreements. Resources Policy 52: 379-388.

Creswell, J. W. and C. Poth. (2007). Qualitative Inquiry \& Research Design Choosing Among Five Approaches. Sage Publications. Thousand Oaks, CA.

Emery, M. and C. Flora. (2006). Spiraling-up: Mapping community transformation with community capitals framework. Community Dev. J. 37(1): 19-35.

Flora, C. B. and J.L. Flora. (2013). Rural communities: Legacy and change, $4^{\text {th }}$ edition. Westview Press, Boulder, CO.
Fortier, J.-F., S. Wyatt, D.C. Natcher, M.A. Smith and M. Hébert. (2013). An inventory of collaborative arrangements between Aboriginal peoples and the Canadian forest sector: Linking policies to diversification in forms of engagement. J. Environ. Manage. 119: 47-55.

Gibson, G. and C. O'Faircheallaigh. (2015). IBA community toolkit. Walter and Duncan Gordon Foundation, Toronto, Canada, https://gordonfoundation.ca/initiatives/iba-toolkit

Gudeman, S. (2008). Economy's tension: the dialectics of community and market. Berghahn Books, New York, N.Y.

Hickey, C. and M. Nelson. (2005). Partnerships between First Nations and the forest sector: A national survey. Sustainable Forest Management (SFM) Network, Edmonton, Alberta. https://era. library.ualberta.ca/files/t722hb08n/SR_200405hickeycpart_en.pdf

Hindle, K. (2010). How community context affects entrepreneurial process: A diagnostic framework. Entrep. Region. Dev. 22(7-8): 599-647.

Hotte, N., R. Kozak and S. Wyatt. (2019). How institutions shape trust during collective action: A case study of forest governance on Haida Gwaii. Forest Policy Econ. 107: 1-13.

Jourdain, A. and S. Naulin. (2019). La sociologie de Pierre Bourdieu. Armand Colin, Paris.

Kant, S. (2003). Extending the boundaries of forest economics. Forest Policy Econ. 5(1): 39-56. https://doi.org/https://doi.org/10.1016/ S1389-9341(02)00045-X

Kayseas, B., P.W. Moroz, R.B. Anderson and L.-P. Dana (2015). Indigenous rights and entrepreneurship: Social capital formation and modes of social regulation. Conference of the Administrative Sciences Association of Canada. Halifax, N.S.

Kernaghan, K. (1993). Partnership and public administration: Conceptual and practical considerations. Can. Publ. Admin. 36(1): 57-76.

Lawler, J. H. and R. Bullock. (2017). A case for Indigenous community forestry. J. Forest. 115(2): 117-125.

Lebaron, F. (2003). Pierre Bourdieu: Economic models against economism. Theory Soc. 32(5): 551-565. https://doi.org/10.1023/ B:RYSO.0000004928.45684.d4

Maclean, K., C.J. Robinson and D.C. Natcher. (2015). Consensus building or constructive conflict? Aboriginal discursive strategies to enhance participation in natural resource management in Australia and Canada. Soc. Natur. Resour. 28(2): 197-211.

Mahanty, S. and C.L. McDermott. (2013). How does 'Free, Prior and Informed Consent' (FPIC) impact social equity? Lessons from mining and forestry and their implications for REDD+. Land Use Policy 35: 406-416.

Mayers, J. and S. Vermeulen. (2002). Company-community forestry partnerships: From raw deals to mutual gains. International Institute for Environment and Development, London.

McCreary, T., S. Mills and A. St-Amand. (2016). Lands and resources for jobs: How Aboriginal peoples strategically use environmental assessments to advance community employment aims. Can. Public Pol. 42(2): 21-223.

McQuaid, R. W. (2000). The theory of partnership: Why have partnerships? Routledge Advances in Management and Business Studies 19: 9-35.

Mills, S. and B. Sweeney. (2013). Employment relations in the neostaples resource economy: Impact benefit agreements and aboriginal governance in Canada's nickel mining industry. Stud. Polit. Econ. 91: 7-34.

Missens, R., L.P. Dana and R. Anderson. (2007). Aboriginal partnerships in Canada: Focus on the Diavik diamond mine. Journal of Enterprising Communities: People and Places in the Global Economy 1(1): 54-76. https://doi.org/10.1108/17506200710736267

O'Faircheallaigh, C. (2010). Aboriginal-mining company contractual agreements in Australia and Canada: Implications for political autonomy and community development. Can. J. Dev. Studies 30(12): 69-86. https://doi.org/10.1080/02255189.2010.9669282 
Paillé, P. and A. Mucchielli. (2012). L'analyse qualitative en sciences humaines et sociales. Armand Colin, Paris.

Parkins, J., R. Stedman, M. Patriquin and M. Burns. (2006). Strong policies, poor outcomes. Longitudinal analysis of forest sector contributions to Aboriginal communities in Canada. J. Aborig. Econ. Dev. 5(1): 61-73.

Perrault, P. and M.G. Stevenson. (2008). Capacity for What? Capacity for Whom?: Aboriginal capacity and Canada's forest sector. Petrucci, F. and R. Tallman. (2011). Developing an economic partnership framework between the Lheidli T'enneh First Nation and Initiatives Prince George Development Corporation. J. Bus. Econ. Res. (JBER) 9(3):

Proulx, G., J.-M. Beaudoin, H. Asselin, L. Bouthillier and D. Théberge. (2020). Untapped potential? Attitudes and behaviours of forestry employers toward the Indigenous workforce in Quebec, Canada. Can. J. For. Res. 50(4): 413-421.

Proulx, M.-U. and I. Diallo. (2016). Socioeconomic dynamics of Aboriginal communities in Quebec. In: Routledge (Ed.), Indigenous People and Economic Development: An International Perspective. Taylor \& Francis, New York, N.Y. pp. 27-44.

Putnam, R. D. (2004). Democracies in flux: The evolution of social capital in contemporary society. Oxford University Press, USA.

Robitaille, P. A., C. Shahi, M.A. Smith and N. Luckai. (2017). Growing together: A principle-based approach to building collaborative Indigenous partnerships in Canada's forest sector. For. Chron. 93(1): 44-57.

Rodon, T., I. Lemus-Lauzon and S. Schott. (2018). Impact and benefit agreement (IBA) revenue allocation strategies for Indigenous Community Development. North. Rev. (47): 9-29.

Rynard, P. (2000). "Welcome in, but check your rights at the door": The James Bay and Nisga'a Agreements in Canada. Can. J. Political Sci. 211-243.

Schein, E. H. (2010). Organizational culture and leadership (Vol. 2). John Wiley \& Sons, San Francisco.
Scoones, I. (1998). Sustainable rural livelihoods: A framework for analysis. IDS Working Paper \#72, Brighton, U.K.

Sosa, I. and K. Keenan. (2001). Impact benefit agreements between aboriginal communities and mining companies: Their use in Canada. Canadian Environmental Law Association, Ottawa.

Teddlie, C. and F. Yu. (2007). Mixed methods sampling: A typology with examples. J. Mix. Method. Res. 1(1): 77-100.

Théberge, D., J.-M. Beaudoin, H. Asselin, J. Ben Mansour, L. Bouthillier, É. St-Jean B. Fabi. (2019). Regards sur les attitudes et comportements des employeurs à l'égard de la diversité de la maind'oeuvre autochtone (rapport global, pp. 1-23), http://hdl. handle.net/20.500.11794/37622

Trosper, R., H. Nelson, G. Hoberg, P. Smith and W. Nikolakis. (2008). Institutional determinants of profitable commercial forestry enterprises among First Nations in Canada. Can. J. For. Res. 38(2): 226-238.

Truth and Reconciliation Commission of Canada. (2015). Truth and Reconciliation Commission of Canada, executive report, Ottawa. https://nctr.ca/assets/reports/Calls_to_Action_English2.pdf Wilson, E. (2019). What is benefit sharing? Respecting Indigenous rights and addressing inequities in Arctic resource projects. Resources 8(2): 1-23.

Wilson, J. and J. Graham. (2005). Relationships between First Nations and the forest industry: The legal and policy context. https://www.nafaforestry.org/docs/pro_forestry.pdf

WGNRD. (2015). Working Group on Natural Resource Development. First Nations and Natural Resource Development : Advancing Positive, Impactful Change. https:/www.afn.ca/uploads/files/ Working-Group-on-Natural-Resource-Development-Report.pdf

Wyatt, S., J.-F. Fortier and C. Martineau-Delisle. (2010). First Nations' involvement in forest governance in Québec: The place for distinct consultation processes. For. Chron. 86(6): 730-741. 